\title{
ANALISIS FAKTOR-FAKTOR YANG MEMPENGARUHI TREND PENURUNAN PELAKSANAAN SENAM IBU HAMIL DI KABUPATEN BEKASI
}

\author{
Siti Jumhati ${ }^{1}$, Slamet Santoso Kurniawan ${ }^{2)}$ \\ ${ }^{1)}$ Program Studi DIII Kebidanan Universitas MH. Thamrin \\ siti_jumie@yahoo.co.id
}

\begin{abstract}
ABSTRAK
Senam Hamil merupakan metode penting untuk mempertahankan atau meningkatkan keseimbangan fisik wanita hamil dan merupakan terapi latihan yang diberikan kepada wanita hamil untuk mencapai kelahiran yang cepat, mudah dan aman (Anggraini 2010). Tujuan Penelitian ini yaitu Menganalisis faktor-faktor apa saja yang mempengaruhi trend penurunan pelaksanaan senam Ibu Hamil di Puskesmas Kabupaten Bekasi. Metode Penelitian yang digunakan adalah deskriptif analitik dengan pendekatan cross sectional, menggunakan penggabungan metode kuantitatif dan kualitatif. Pengambilan sampel menggunakan teknik purposive sampling yaitu 70 responden. Dari hasil penelitian yang telah dilakukan di puskesmas Kab Bekasi, berdasarkan responden yang mempunyai motivasi yang tinggi adalah sebanyak 49 orang (70\%), dan yang memiliki motivasi rendah adalah sebanyak 21 orang (30\%), berdasarkan responden yang mempunyai minat yang tinggi adalah sebanyak 50 orang $(71,4 \%)$, dan yang memiliki minat rendah adalah sebanyak 20 orang $(28,6 \%)$. Berdasarkan responden yang tidak bekerja adalah sebanyak 33 orang $(47,1 \%)$, dan yang bekerja adalah sebanyak 37 orang $(52,9 \%)$, berdasarkan responden yang tidak mendapatkan dukungan suami/keluarga adalah sebanyak 26 orang $(37,1 \%)$, dan yang mendapatkan dukungan suami/keluarga adalah sebanyak 44 orang $(62,9 \%)$, berdasarkan responden yang tidak mendapatkan dukungan petugas kesehatan adalah sebanyak 18 orang $(25,7 \%)$, dan yang mendapatkan dukungan petugas kesehatan adalah sebanyak 52 orang $(74,3 \%)$. Dari 4 variabel yang diteliti dan berdasarkan hasil dari cross tabulasi didapatkan bahwa 3 variabel independent berhubungan dengan variabel dependent yaitu minat, dukungan suami dan dukungan petugas kesehatan. Sedangkan variabel independent yang tidak berhubungan dengan variabel dependent adalah pekerjaan. Kesimpulan Dan Saran : Penulis mengharapkan agar petugas kesehatan dapat meningkatkan pelayanan kesehatan terutama di kelas senam hamil dengan selalu melaksanakan kelas senam hamil di waktu yang tepat agar ibu hamil termotivasi dan mau melaksanakan senam hamil.
\end{abstract}

Kata Kunci : Motivasi, Minat, Pekerjaan,Dukungan Suami/Keluarga, Dukungan Petugas Kesehatan Ibu Hamil Dan Senam Hamil.

\section{PENDAHULUAN}

Senam hamil merupakan salah satu kegiatan dalam pelayanan selama kehamilan atau prenatal care yang bertujuan untuk mempersiapkan dan melatih otot - otot sehingga dapat diimanfaatkan secara optimal dalam persalinan normal (Anggraeni, 2010). Senam hamil sangat penting dilakukan oleh ibu hamil setelah kehamilan mencapai 22 minggu, salah satu manfaat senam hamil adalah dapat mengurangi terjadinya berat badan bayi lahir rendah, mengurangi terjadinya persalinan premature (Anggraeni, 2010).

Pada beberapa penelitian didapatkan bahwa berat janin yang lahir dari wanita hamil yang melakukan senam/olahraga selama kehamilannya lebih berat dibanding yang tidak melakukan olahraga, hal ini dapat diterangkan mengingat olahraga akan meningkatkan aliran darah ke uterus yang merupakan jalan terpenting bagi suplai nutrien dan metabolisme janin. Wanita hamil yang melakukan latihan - latihan selama kehamilannya akan memiliki plasenta yang lebih berat akibat meningkatnya placental blood flow, dengan demikian nutrisi ke janin akan menjadi lebih baik. Pada penelitian yang dilakukan oleh Supriatmaja dengan judul "Pengaruh Senam Hamil Terhadap Berat Badan Janin" di RSUD Bogor tahun 2006, didapatkan data 
bayi yang dilahirkan oleh ibu yang melakukan senam pada penelitian ini lebih berat, yaitu 3200,00 $\pm 363 \mathrm{~g}$. berbanding $3072,17 \pm 327 \mathrm{~g}$.

Manfaat lain senam hamil yaitu dapat meningkatkan konsumsi oksigen untuk tubuh, aliran darah jantung, stroke volume dan curah jantung (Anggraeni, 2010). Gerakan pada senam hamil menyebabkan peredaran darah dalam tubuh akan meningkat dan oksigen yang diangkut ke otot - otot dan jaringan tubuh bertambah banyak. Gerakan senam hamil dapat meningkatkan tekanan darah dan menyebabkan perubahan tekanan osmotik intramuskuler sehingga mendorong air dari kompartemen vaskuler ke ruang interstitial sehingga volume plasma turun dan secara otomatis menaikkan kadar hemoglobin ( $\mathrm{Hb}$ ). Pada penelitian yang dilakukan oleh Qhotrun Nida dengan judul "Pengaruh Senam Hamil Terhadap Perubahan Kadar Hb pada Kehamilan Trimester Tiga" di RS Muhammadiyah tahun 2009 didapatkan data 26\% ibu yang tidak melakukan senam hamil mengalami penurunan $\mathrm{Hb}$ di trimester ketiga dan $7 \%$ ibu yang melakukan senam hamil mengalami penurunan $\mathrm{Hb}$.

Penelitian yang dilakukan oleh Budiman tahun 2001 dengan judul "Hubungan Senam Hamil dengan Proses Persalinan pada Ibu yang Melahirkan di RS Setia Mitra", diperoleh hasil 8\% ibu melahirkan yang mengikuti senam hamil mengalami inersia uteri dan $14,5 \%$ ibu yang tidak mengikuti senam hamil mengalami inersia uteri. Data ini menunjukan bahwa senam hamil dapat menurunkan prosentase kejadian inersia uteri.

Berdasarkan studi pendahuluan yang telah di lakukan di Puskesmas Kabupaten Bekasi pada tanggal 2 Januari 2016 di Bagian Rekam Medik didapatkan bahwa dalam tiga tahun terakhir terlihat adanya trend penurunan angka senam hamil yaitu sebanyak 61 ibu hamil (0.26\%) pada tahun 2010, pada tahun 2011 sebanyak $51 \mathrm{ibu}$ hamil (O,24\%), pada tahun 2012 sebanyak 49 ibu hamil (0.22\%) dan pada tahun 2013 sebanyak 40 ibu hamil $(0.13 \%)$. Berdasarkan hal tersebut penelitian ini perlu dilakukan untuk mengetahui faktor-faktor apa saja yang mempengaruhi trend penurunan pelaksanaan senam Ibu Hamil di Puskesmas Kabupaten Bekasi Tahun 2016.

\section{METODE}

Penelitian ini bersifat deskriptif analitik dengan disain Cross Sectional menggunakan penggabungan metode kuantitatif dan kualitatif untuk mengetahui faktor-faktor yang mempengaruhi trend penurunan pelaksanaan senam ibu hamil di Puskesmas Kabupaten Bekasi Tahun 2016. Populasi dalam penelitian ini adalah semua ibu hamil usia kehamilan > 22 minggu yang datang periksa ke 39 Puskesmas Kabupaten Bekasi Tahun 2016 tetapi yang aktif melaksanakan senam hamil hanya 5 puskesmas : Puskesmas Sri Amur, Puskesmas Cikarang, Puskesmas Kedung Waringin, Puskesmas Mekar Mukti, Puskesmas Cabang Bungin, dengan rata2 kunjungan senam hamil setiap bulan berkisar antara 10-20 orang per puskesmas. Pengambilan sampel menggunakan teknik purposive sampling yaitu 70 sampel.

\section{HASIL DAN PEMBAHASAN}

\section{Karakteristik Sampel}

Karakteristik sampel dalam penelitian ini adalah motivasi ibu hamil, minat ibu hamil, pekerjaan ibu hamil, 
dukungan suami/keluarga, dukungan petugas kesehatan dan pelaksanaan senam hamil.

Tabel 1.

Karakteristik Sampel Berdasarkan motivasi ibu hamil, minat ibu hamil, pekerjaan ibu hamil, dukungan suami/keluarga, dukungan petugas kesehatan dan pelaksanaan senam hamil. di wilayah Puskesmas Kabupaten Bekasi Tahun 2017.

\begin{tabular}{lcc}
\hline & Karakteristik sampel & \\
\hline Motivasi & Jumlah (orang) & Persentasi (\%) \\
\hline Tinggi & 20 & $30 \%$ \\
\hline Rendah & 50 & $70 \%$ \\
\hline Total & 70 & $100 \%$ \\
\hline Minat & & \\
\hline Tinggi & 20 & $28,6 \%$ \\
\hline Rendah & 50 & $71,4 \%$ \\
\hline Total & 70 & $100 \%$ \\
\hline Pekerjaan & & $52,9 \%$ \\
\hline Bekerja & 37 & $47,1 \%$ \\
\hline Tidak Bekerja & 33 & 100 \\
\hline Total & 70 & \\
\hline Dukungan suami/ & & $62,9 \%$ \\
keluarga & & $37,1 \%$ \\
\hline Mendukung & 44 & $100 \%$ \\
\hline Tidak Mendukung & 26 & \\
\hline Total & 70 & $74,3 \%$ \\
\hline Dukungan Petugas & & $25,7 \%$ \\
\hline Kesehatan & 52 & 100 \\
\hline Mendukung & 18 & \\
\hline Tidak mendukung & 70 & \\
\hline Total & & \\
\hline
\end{tabular}

Sebagian besar sampel memiliki motivasi rendah ( $70 \%)$, minat rendah ( 71,4 \%) minat ibu hamil, bekerja $(47,1 \%)$, dukungan suami/keluarga(62,9\%), dukungan petugas kesehatan(74,3\%), dan tidak melakukan senam hamil ( $70 \%)$.

Dari tabel diatas sebagian besar sampel memiliki motivasi rendah ( $70 \%)$, minat rendah $(71,4 \%)$ minat ibu hamil, bekerja $(47,1 \%)$, dukungan suami/keluarga(62,9\%), dukungan petugas kesehatan(74,3\%), dan tidak melakukan senam hamil ( $70 \%$ ). Hasil uji statistik maka dapat disimpulkan bahwa ada hubungan antara minat, motivasi, dukungan suami/keluarga, dukungan petugas kesehatan dengan pelaksanaan senam hamil dengan nilai masing-masing $\mathrm{p}$ value $=0,04, \mathrm{p}$ value $=0,02$, dan $\mathrm{p}$ value $=0,02$. Kemudian diperoleh bahwa tidak ada hubungan antara pekerjaan dengan pelaksanaan senam hamil dengan $\mathrm{p}=0,17$. 


\section{Hasil Analisis Hubungan}

Tabel 2

Hubungan antara motivasi ibu hamil, minat ibu hamil, pekerjaan ibu hamil, dukungan suami/keluarga, dukungan petugas kesehatan dengan pelaksanaan senam hamil di Puskesmas Kabupaten Bekasi Tahun 2017

\begin{tabular}{|c|c|c|c|c|c|c|c|}
\hline \multirow{3}{*}{ Motivasi } & \multicolumn{6}{|c|}{ Pelaksanaan senam hamil } & \multirow{3}{*}{ P Value } \\
\hline & \multicolumn{2}{|c|}{$\begin{array}{c}\text { Tidak } \\
\text { melakukan }\end{array}$} & \multicolumn{2}{|c|}{ Melakukan } & \multicolumn{2}{|c|}{ Jumlah } & \\
\hline & $\mathbf{F}$ & $\%$ & $\mathbf{F}$ & $\%$ & $\mathbf{N}$ & $\%$ & \\
\hline$\overline{\text { Tinggi }}$ & 10 & 14,3 & 10 & 14,3 & 20 & 28,6 & 0,04 \\
\hline Rendah & 11 & 15,7 & 39 & 49,4 & 50 & 71,4 & \\
\hline Jumlah & 21 & 30 & 49 & 70 & 70 & 100 & \\
\hline \multicolumn{8}{|l|}{ Minat } \\
\hline Tinggi & 10 & 14,3 & 10 & 14,3 & 20 & 28,6 & \\
\hline Rendah & 11 & 15,7 & 39 & 49,4 & 50 & 71,4 & \\
\hline Jumlah & 21 & 30 & 49 & 70 & 70 & 100 & \\
\hline \multicolumn{8}{|l|}{ Pekerjaan ibu } \\
\hline Bekerja & 8 & 11,4 & 29 & 41,4 & 37 & 52,9 & \\
\hline Tidak Bekerja & 13 & 18,6 & 20 & 28,6 & 33 & & 0,17 \\
\hline Jumlah & 21 & 30 & 49 & 70 & 70 & $100 \%$ & \\
\hline
\end{tabular}

\begin{tabular}{lcccccc}
\hline $\begin{array}{l}\text { Dukungan Suami/ } \\
\text { Keluarga }\end{array}$ & & & & & \\
\hline $\begin{array}{l}\text { Tidak } \\
\text { mendukung }\end{array}$ & 3 & 4,3 & 23 & 32,9 & 26 & 37,1 \\
\cline { 2 - 7 } Mendukung & 18 & 25,7 & 26 & 37,1 & 44 & 0,02 \\
\hline Jumlah & 21 & 30 & 49 & 70 & 70 & 100 \\
\hline
\end{tabular}

Dukungan petugas kesehatan

\begin{tabular}{lcccccc} 
Tidak mendukung & 11 & 15,7 & 7 & 10 & 18 & 25,7 \\
\cline { 2 - 7 } & & & & & & 0,002 \\
\hline Mendukung & 10 & 14,3 & 42 & 60 & 52 & 74,3 \\
\hline Jumlah & 21 & 30 & 49 & 70 & 70 & 100 \\
\hline
\end{tabular}

\section{Pembahasan}

\section{Motivasi}

Dari hasil penelitian yang telah dilakukan di puskesmas Kab Bekasi, berdasarkan responden yang mempunyai motivasi yang rendah adalah sebanyak 50 orang $(71,4 \%)$, dan yang memiliki motivasi tinggi adalah sebanyak 20 orang (28,6\%).Berdasarkan hasil penelitian didapatkan bahwa motivasi ibu hamil dalam melakukan senam hamil rendah. Hal ini sesuai dengan hasil penelitian yang telah dilakukan oleh Kasinia (2009), menyatakan bahwa motivasi ibu hamil dalam melakukan senam hamil sangat rendah.Seseorang akan berhasil jika memiliki motivasi tinggi untuk mencapai keinginannya. tanpa motivasi dalam melakukan kegiatan tidak akan terarah dan sungguh-sungguh (Sukmadinata, 2008).

Menurut peneliti dengan hasil penelitian di puskesmas Kab Bekasi, sudah banyak ibu hamil yang memiliki motivasi tinggi untuk melakukan senam hamil. Motivasi tidak dapat dipisahkan dari kebutuhan seseorang yang 
melakukan sesuatu. Motivasi menunjukkan ada proses gerakan termasuk situasi yang timbul dari diri individu, tingkah laku yang ditimbulkan oleh situasi tersebut. Hal ini disebabkan karena ibu kurangmendapatkan informasi mengenai senam hamil. Hal ini yang menjadi penyebab ibu hamil tidak melakukan senam hamil.

Oleh karena itu, memberikan informasi kepada ibu hamil mengenai senam hamil sangat penting. Dengan kita memberikan informasi ibu menjadi termotivasi untuk melakukan senam hamil. Informasi itu bisa didapatkan dari petugas kesehatan yang memberikan penyuluhan atau dengan ibu yang aktif dalam mencari informasi di media dan lainnya.

\section{Minat}

Dari hasil penelitian yang telah dilakukan di puskesmas Kab Bekasi, berdasarkan responden yang mempunyai minat yang rendah adalah sebanyak 50 orang $(71,4 \%)$, dan yang memiliki minat tinggi adalah sebanyak 20 orang $(28,6 \%)$.

Menurut Djaali (2012), terdapat beberapa faktor yang dapat mempengaruhi timbulnya minat seseorang ibu dalam melakukan senam hamil yaitu faktor ekonomi, pendidikan dan tempat tinggal atau lingkungan.

Menurut peneliti minat ibu hamil di Puskesmas Kab bekasi rendah.dalam melakukan senam hamil. Hal ini membuktikan bahwa ibu hamil belum sadar akan pentingnya senam hamil untuk kesehatan baik ibu dan bayinya, terutama dalam persiapan untuk persalinan nanti.

Oleh karena itu untuk minat ibu hamil dalam melakukan senam hamil tetap dipertahankan jangan sampai minat itu menjadi menurun.

\section{Pekerjaan Ibu}

Dari hasil penelitian yang telah dilakukan di puskesmas Kab Bekasi , berdasarkan responden yang tidak bekerja adalah sebanyak 33 orang $(47,1 \%)$, dan yang bekerja adalah sebanyak 37 orang $(52,9 \%)$.

Pekerjaan merupakan sesuatu hal yang dikerjakan untuk mendapatkan imbalan atau balas jasa (Notoadmodjo,2010).

Menurut peneliti pekerjaan merupakan upaya mencapai kesejahteraan untuk manusia dalam hidup. Namun pekerjaan bukanlah menjadi penghambat untuk ibu dalam melakukan senam hamil atau kelas ibu hamil yang dimana senam hamil mempunyai manfaat yang cukup banyak selama kehamilan dan proses persalin. Pekerjaan tidaklah menjadikan ibu untuk tidak memperhatikan keadaan bayinya.

Oleh karena itu, ibu yang tidak bekerja seharusnya lebih banyak waktunya untuk melakukan senam hamil baik di pelayanan kesehatan maupun di rumah daripada ibu hamil yang bekerja.

\section{Dukungan Suami/Keluarga}

Dari hasil penelitian yang telah dilakukan di puskesmas Kab Bekasi, berdasarkan responden yang tidak mendapatkan dukungan suami/keluarga adalah sebanyak 26 orang (37,1\%), dan yang mendapatkan dukungan suami/keluarga adalah sebanyak 44 orang (62,9\%). Dukungan suami/keluarga merupakan suatu bentuk perwujudan dari sikap perhatian dan kasih sayang. Dukungan dapat diberikan baik fisik maupun psikis. Suami memiliki andil yang cukup besar dalam menentukan status kesehatan ibu. Dukungan suami yang baik dapat 
memberikan motivasi yang baik ada ibu hamil (Eko, 2008).

Menurut peneliti pengetahuan suami tentang perannya dalam senam hamil sangatlah baik walaupun masih ada kendala dalam kepercayaan, budaya dan agama yang menjadi tantangan dalam pelaksanaan program tersebut. Akan tetapi hal tersebut dapat diatasi dengan dukungan dan keterlibatan tokoh masyarakat dan agama. Untuk meningkatkan peran suami dalam kesehatan yaitu membekali suami dengan informasi yang benar dan mengikutsertakan dalam setiap upaya peningkatan kesehatan ibu hamil, suami merupakan partner untuk mencapai kesehatan yang lebih baik. Oleh karena itu, dukungan dan peran serta suami dalam masa kehamilan terbukti meningkatkan kesiapan ibu hamil dalam menghadapi proses persalinan, bahkan juga memicu produksi ASI, secara tidak langsung akan memberi manfaat emosional yang dapat menambah kekuatan istri dalam melawan rasa takut dan cemas sehingga proses persalinan pada kala II dapat berjalan lebih cepat.

\section{Dukungan Petugas Kesehatan}

Dari hasil penelitian yang telah dilakukan di puskesmas Kab Bekasi, berdasarkan responden yang tidak mendapatkan dukungan petugas kesehatan adalah sebanyak 18 orang (25,7\%), dan yang mendapatkan dukungan petugas kesehatan adalah sebanyak 52 orang $(74,3 \%)$.

Hubungan yang telah lama dilakukan antara seseorang sebagai pasien, bidan atau dokter sebagai tenaga kesehatan, akan memiliki pengaruh terhadap tingkat kepatuhan yang diberikan kepada tenaga kesehatan. Pasien yang telah mengenal dengan baik terhadap tenaga kesehatan tempat berobat, maka ia akan cenderung lebih patuh dari pada terhadap mereka yang belum begitu dikenal. Begitu pula penanganan oleh tenaga kesehatan terhadap pasiennya (Shintha, 2008).

Menurut peneliti sudah baik pelayanan konseling senam hamil dan dukungan dari petugas. Hal ini membuktikan bahwa tenaga kesehatan sudah memberikan informasi yang cukup tentang senam hamil.

Oleh karena itu, bagi petugas kesehatan sebaiknya dapat bekerja sama dan membangun hubungan yang baik dengan klien agar terjalin hubungan yang terbuka antara petugas kesehatan dan klien. Karena petugas kesehatan juga sebagai fasilitator.

\section{Hubungan Antara Motivasi dan Minat dengan pelaksanaan senam hamil}

Hasil cross tabulasi menunjukan hasil uji statistic Chi-Square diperoleh nilai masing-masing p.0,04 (p.Value < $0,05)$ yang berarti berarti Ho ditolak artinya ada hubungan yang bermakna antara minat dengan motivasi ibu hamil dalam melakukan senam hamil.

Minat merupakan salah satu aspek psikis manusia yang dapat mendorong untuk mencapai tujuan. Seseorang yang memiliki minat terhadap suatu obyek, cenderung untuk memberikan perhatian atau merasa senang yang lebih besar kepada obyek tersebut. Namun apabila obyek tersebut tidak menimbulkan rasa senang, maka ia tidak akan memiliki minat ada obyek tersebut. Crow berpendapat bahwa minat erat hubungannya dengan daya gerak yang mendorong seseorang untuk menghadapi atau berurusan dengan orang, benda atau bisa juga sebagai pengalaman efektif yang dipengaruhi oleh kegiatan itu sendirii (Slamet, 2010).

Berdasarkan hasil penelitian Rini Lana (2009), didapatkan nilai $\mathrm{p}=0,042$ berarti $\mathrm{p}<0,05$, yang menyatakan 
bahwa minat ada hubungan dengan motivasi ibu hamil dalam mengikuti senam hamil. Adapun faktor penghambat bisa dipengaruhi minat ibu dalam mengikuti senam hamil yaitu rasa malas, rumah ibu jauh dari fasilitas kesehatan. Padahal di fasilitas kesehatan tidak memungut biaya untuk pelaksanaan kelas senam hamil (Aviyanti, 2010).

Menurut peneliti dalam hal ini sesuai dengan hasil penelitian Rini. Karena menurut peneliti motivasi itu terlahir dari dalam diri manusia itu sendiri yang timbul secara sadar maupun tidak sadar. Sedangkan minat itu hanya mengarahkan perbuatan kepada suatu tujuan atau dorongan manusia untuk berbuat lebih giat dan lebih baik. Jadi, apabila didalam diri ibu hamil tidak ada minat untuk melakukan senam hamil tidak akan memengaruhi motivasi ibu hamil dalam melakukan senam hamil.

Dengan demikian, sangatlah penting ibu hamil memiliki minat. Edukasi merupakan salah satu cara untuk menimbulkan minat ibu hamil agar ibu hamil tergerak untuk melakukan senam hamil.

\section{Hubungan Antara Pekerjaan Ibu dengan pelaksanaan senam hamil}

Hasil cross tabulasi antara variabel pekerjaan dengan motivasi dalam melakukan senam hamil menunjukan hasil uji statistic Chi-Square diperoleh nilai p.0,17 (p.Value > 0,05) yang berarti berarti Ho diterima artinya tidak ada hubungan yang bermakna antara pekerjaan dengan motivasi ibu hamil dalam melakukan senam hamil.

Status pekerjaan menggambarkan tingkat kesibukan ibu hamil dalam rumah tangga. Selain itu, status pekerjaan juga dapat menggambarkan sosial ekonomi dalam keluarga (Notoadmodjo, 2008).

Hasil penelitian ini sesuai dengan penelitian rohani (2008), didapatkan $=0,65$ yang berarti $=>0,05$, yang juga menyatakan bahwa pekerjaan ibu tidak ada hubungannya dengan motivasi ibu hamil dalam melakukan senam hamil. Hal ini dikarenakan mereka terlalu sibuk dan tidak ada waktu untuk mengikuti senam hamil secara rutin. Menurut pendapat peneliti hal ini sesuai dengan hasil penelitian bahwa tidak ada hubungannya antara pekerjaan ibu hamil dengan motivasi ibu hamil dalam mengikuti senam hamil. Karena apabila ibu hamil yang melakukan senam hamil tidak hanya bisa di lakukan di fasilitas kesehatan saja, tetapi bisa juga di lakukan di rumah. Apabila ibu hamil yang bekerja bisa melakukan senam hamil di tempat dimana ia bekerja. Asalkan ibu dapat menyempatkan waktu untuk melakukan senam hamil. Padahal bekerja bukanlah alasan ibu untuk tidak dapat melakukan senam hamil.

Oleh karena itu, sangatlah penting bagi tenaga kesehatan untuk mengadakan senam hamil di tempat lain seperti di posyandu terdekat yang mudah dijangkau. Dan melakukan senam hamil di waktu senggang. Seperti di hari minggu atau di hari yang sekiranya para ibu yang bekerja dapat melakukan senam hamil.

\section{Hubungan antara dukungan suami/keluarga dengan pelaksanaan senam hamil}

Hasil cross tabulasi antara variabel dukungan suami/keluarga dengan motivasi dalam melakukan senam hamil menunjukan hasil uji statistic Chi-Square diperoleh nilai p.0,02 (p.Value < 0,05) yang berarti berarti Ho ditolak artinya ada hubungan yang bermakna antara dukungan suami/keluarga dengan motivasi ibu hamil dalam melakukan senam hamil.

Dukungan suami/keluarga merupakan suatu bentuk perwujudan dari sikap perhatian dan kasih sayang. 
Dukungan dapat diberikan baik fisik maupun psikis. Suami memiliki andil yang cukup besar dalam menentukan status kesehatan ibu. Dukungan suami yang baik dapat memberikan motivasi yang baik pada ibu hamil (Eko, 2008).

Komunikasi antar pasangan merupakan salah satu faktor penting peningkatan angka kejadian ibu dalam melakukan senam hamil. Komunikasi akan membantu ibu hamil dalam mendorong adanya kesetaraan dalam pengambilan keputusan.

Hal ini sejalan dengan penelitian sebelumnya yang dilakukan oleh kemalasari (2008), berdasarkan hasil penelitian didapatkan hasil 0,025 yang berarti $<0,05$ bahwa hasil penelitian menunjukkan bahwa variabel dukungan suami/keluarga memengaruhi motivasi ibu hamil dalam melakukan senam hamil.

Menurut pendapat peneliti hal ini sesuai dengan hasil penelitian bahwa ada hubungan yang sangat berarti antara dukungan suami/keluarga dengan motivasi ibu hamil dalam melakukan senam hamil. Karena, dukungan suami/keluarga sangat memengaruhi terhadapat motivasi ibu dalam melakukan senam hamil, dengan dukungan suami/keluarga ibu hamil merasa diperhatikan dan disayang atas kehamilannya. Dukungan suami yang diberikan oleh suami kepada istrinya dalam bentuk verbal dan non verbal.

Oleh karena itu, sangatlah penting untuk suami/keluarga dalam memberikan dukungan kepada istri. Karena dari dukungan akan ada motivasi yang timbul dari diri ibu. dukungan bisa seperti perhatian dan kasih sayang.

\section{Hubungan antara dukungan petugas kesehatan dengan pelaksanaan senam hamil}

Berdasarkan analisis data hubungan antara motivasi ibu hamil dengan dukungan petugas kesehatan dapat diketahui bahwa dari 70 responden ibu dengan motivasi tinggi yang terbesar pada ibu yang mendapat dukungan petugas kesehatan sebanyak 42 (60\%), sedangkan pada ibu dengan motivasi rendah yang terbesar pada ibu yang tidak mendapat dukungan petugas kesehatan sebanyak 11 (15,7\%).

Hasil cross tabulasi antara variabel dukungan suami/keluarga dengan motivasi dalam melakukan senam hamil menunjukan hasil uji statistic Chi-Square diperoleh nilai p.0,002 (p.Value < 0,05) yang berarti berarti Ho ditolak artinya ada hubungan yang bermakna antara dukungan petugas kesehatan dengan motivasi ibu hamil dalam melakukan senam hamil.

Petugas kesehatan khususnya bidan berperan penting dalam keberhasilan senam hamil pada ibu hamil, bidan mengajarkan pada ibu tentang tatacara senam hamil. Bidan juga memberikan dukungan masih kepada ibu agar dapat menjalankan senam hamil secara rutin pada saat masa kehamilan (Posdinkes, 2010).

Petugas kesehatan sebagai orang yang disegani oleh oleh masyarakat, merupakan salah satu kelompok refensi bagi terbentuknyaa motivasi seseorang, yang dalam hal ini adalah motivasi ibu dalam melakukan senam hamil. Dengan adanya informasi-informasi yang jelas tentang senam hamil dari petugas kesehatan. Akan menambah pemahaman ibu hamil tentang senam hamil (Notoatmodjo, 2009).

Berbeda dengan hasil penelitian Arora (2008), didapatkan hasil uji statistik $\mathrm{p}=0,444$ yang berarti $>0,05$ tidak ada hubungan antara dukungan petugas kesehatan dengan motivasi ibu hamil dalam melakukan senam hamil. Sedangkan hasil penelitian ini sesuai dengan penelitian yang dilakukan oleh sofyan (2009). Di dapatkan bahwa ada hubungan antara petugas kesehatan dengan motivasi ibu hamil dalam melakukan senam hamil. 
Menurut pendapat peneliti hal ini sesuai dengan hasil penelitian bahwa ibu hamil yang tidak termotivasi untuk melakukan senam hamil bukan berarti ibu hamil tersebut tidak mendapat dukungan dari petugas kesehatan. petugas kesehatan hanya sebagai alat untuk memberikan informasi kepada ibu hamil. Dalam hal ini petugas kesehatan sangatlah berperan penting.

Oleh karena itu, sangatlah penting untuk petugas kesehatan selalu memberikan motivasi terhadap ibu hamil untuk melakukan senam hamil memberikan edukasi/penyulahan kepada ibu hamil mengenai senam hamil dan lebih meningkatkan pelaksaan kelas senam hamil yang sudah dilaksanakan selama ini. Di sini petugas kesehatan di butuhkan partisipasi dalam meningkatkan pelaksanaan kelas senam hamil tersebut. Di sarankan kepada petugas kesehatan untuk selalu memberikan informasi baik secara langsung maupun tidak langsung.

\section{KESIMPULAN DAN REKOMENDASI}

Berdasarkan distribusi frekuensi pelaksanaan senam hamil di Puskesmas Kab Bekasi diketahui bahwa dari 70 responden yang memiliki motivasi rendah sebanyak 49 (70\%) dan yang memiliki motivasi sebanyak tinggi 21 (30\%); Dari 4 variabel yang diteliti dan berdasarkan hasil dari cross tabulasi didapatkan bahwa 3 variabel independent berhubungan dengan variabel dependent yaitu motivasi, minat, dukungan suami dan dukungan petugas kesehatan. Sedangkan variabel independent yang tidak berhubungan dengan variabel dependent adalah pekerjaan. Bagi Tenaga Kesehatan, Petugas kesehatan sangatlah berperan penting untuk meningkatkan pelayanan pada kelas senam hamil seperti mengadakan penyuluhan, memasang spanduk dan membagikan brosur mengenai senam hamil. Serta memberi tahu manfaat dan tujuan dari senam hamil tersebut. Agar ibu hamil bisa mendapatkan informasi yang lebih dalam mengenai senam hamil; Dalam hal ini petugas kesehatan sebaiknya membuat jadwal kelas senam hamil yang sekiranya dapat dilakukan sesuai dengan jadwal/hari yang tepat agar ibu hamil dapat melakukan senam hamil tanpa alasan waktu; Petugas kesehatan harus lebih meningkatkan penyuluhan-penyuluhan mengenai kesehatan terutama senam hamil di pelayanan kesehatan. Bagi Puskesmas Kab Bekasi, Di harapkan Puskesmas Kab Bekasi untuk lebih bisa meningkatkan pelayanan kesehatan terutama di kelas senam hamil. Dengan selalu melaksanakan kelas senam hamil di waktu yang tepat. Agar ibu hamil bisa melaksanakan senam hamil; Dalam hal ini pihak petugas dari puskesmas Kab Bekasi juga diharapkan untuk mempertahankan dukungannya yang sudah baik terhadap ibu hamil dalam meningkatkan pelayanan.

\section{REFERENSI}

1. Agnesti.R, dan Linggarjati. 2009. Senam Hamil Praktis. Jakarta: Buku Kita

2. Anggraeni.2010. Serba - Serbi Senam Hamil.Yogyakarta: Info Medika

3. Arora. 2008. Hubungan senam hamil dan persalinan. Journal

4. Arif,Syamsul.2007. Peningkatan kekuatan otot yang terlibat dalam proses meneran yang diukur dengan parameter fve setelah melakukan senam hamil. Program Studi Ilmu Kedokteran Dasar Dan Biomedik,Sekolah Pasca Sarjana,Universitas Gadjah Mada,Yogyakarta 
5. Avianti. 2010 Faktor penghambat dalam senam hamil. Journal Bragshaw.2009.Senam Hamil dan Nifas. Pedoman praktis bidan, Jakarta: EGC

6. Budiman,2001 dengan judul "Hubungan Senam Hamil dengan Proses Persalinan pada Ibu yang Melahirkan di RS Setia Mitra. Jakarta"

7. Diawina, 2009. Buku Panduan Senam Hamil, Jakarta: media persindo

8. Djaali, 2012.Psikologi Pendidikan. Jakarta: Bumi Aksara.

9. Hanton, Ibu Kuat Bayi Sehat. Panduan Senam Kebugaran Untuk Wanita Hamil. Jakarta: Pt.Roja Grafindo Persada

10. Kemalasari. 2008. Kecemasan menghadapi masa persalinan ditinjau dari keikut sertaan ibu dalam senam hamil. journal

11. Linggarjati, 2011. Senam Hamil Praktis, Jakarta: Media Persindo

12. Mandriawati, 2008. Penuntun Belajar Asuhan Kebidanan Ibu Hamil. Jakarta: EGC

13. Notoadmodjo, 2010.Metode Penelitian Kesehatan. Jakarta: RinekaCipta Puerwodarminto. 2009. Kamus Besar Bahasa Indonesia.Jakarta Alfabeta Purwanto, ngalim.2010. Psikologi Pendidilkan. Bandung: remaja

14. Pos DinKes. 2010. Dukungan tenaga kesehatan dalam senam hamil. Batampos Newspaper

15. Qhotrun Nida, 2009.“Pengaruh Senam Hamil Terhadap Perubahan Kadar Hb pada Kehamilan Trimester Tiga" di RS Muhammadiyah. Jakarta

16. Renvilla, 2009. 30 Menit Panduan Senam Hamil Dirumah Anda.Jakrta: Media Presindo

17. Shinta. 2008. Peran petugas kesehatan dalam melakukan senam hamil dan senam nifas. Journal

18. Sofyan.2009. Pengaruh Minat Terhadap Motivasi Ibu Mengikuti Senam Hamil.Jakarta: Rineka Cipta

19. Suganda, adi.2009. Dukungan Suamil Pendorong Keberhasilan Senam Hamil. Diakses pada tanggal 22 Juni 2014.Dalamwebsite:http/www.f.buzz.com.

20. Supriatmaja 2006, "Pengaruh Senam Hamil Terhadap Berat Badan Janin” di RSUD Bogor. Jawa Barat

21. Yuliarti, 2010. Panduan Lengkap Olahraga Bagi Wanita Hamil Dan Menyusu.Yogyakarta

22. Yuliasari, 2010. Skripsi Hubungan Pengetahuan dan Sikap dengan Pelaksanaan Senam Hamil (Studi pada Ibu Hamil Trimester II dan III ) di Puskesmas Ciputat Tangerang Selatan. Jakarta. Universitas Islam Negeri Syarif Hidayatullah.

23. Wulandari. 2009. Efektifitas SenamHamil SebagaiPelayanan Prenatal Dalam Menurunkan Kecemasan Menghadapi Persalinan Pertama. Fakultas psikologi airlangga. Diakses pada tanggal, 22 juni 2014. 